\title{
COVID Abdomen: SARS-CoV-2 Infection Presenting as 'Acute Abdomen' in a Child
}

\author{
Muthiah Periyakaruppan ${ }^{1}$. Sandip Kumar ${ }^{1}$ - Sasidaran Kandasamy ${ }^{1}$ (D) Thangavelu Sangaralingam $^{2}$. \\ Sundaram Srinivasan ${ }^{3}$. Anand Thiagarajan ${ }^{4}$. Nandhini Ganapathy ${ }^{5}$
}

Received: 7 June 2020 / Accepted: 16 September 2020/ Published online: 23 September 2020

(C) Dr. K C Chaudhuri Foundation 2020

To the Editor: Despite lesser incidence and disease severity of COVID-19 in children, growing evidence suggests huge heterogeneity in clinical presentation [1]. We describe an 11-yold boy, who presented with fever, pain abdomen for five days, vomiting, loose stool for three days, transient non-itchy, maculopapular rashes on both feet. At admission, he had diffuse abdominal tenderness with guarding. He was kept nil by mouth and started on intravenous maintenance fluid and ceftriaxone. Initial blood investigations showed Hemoglobin $11.6 \mathrm{~g} / \mathrm{dl}$; total leukocyte count (TLC) - 11,500 cells $/ \mathrm{mm}^{3}$ with $90 \%$ neutrophils $(\mathrm{N})$ and $9 \%$ lymphocytes (L), Platelets -3.0 Lakhs $/ \mathrm{mm}^{3}, \mathrm{CRP}-107 \mathrm{mg} / \mathrm{L}$, hypoalbuminemia $(2.6 \mathrm{~g} /$ dl), INR 1.46, Ferritin 666 ng/ml, LDH 233 U/L with preserved renal function, lactate and transaminases. CT abdomen revealed normal appendix, diffuse mural wall thickening in the terminal ileum and ascending colon with adjacent significant mesenteric lymphadenopathy. COVID-19 RT-PCR from the nasopharyngeal and oropharyngeal samples were negative. On day 3 of hospitalization child developed features of shock, required $40 \mathrm{ml} / \mathrm{kg}$ crystalloid fluid resuscitation. On extended evaluation, 2D ECHO was normal, CRP increased to $142 \mathrm{mg} / \mathrm{L}$, D-dimer was high $(2.16 \mathrm{mg} / \mathrm{L})$ with negative

Sasidaran Kandasamy

sasidarpgi@gmail.com

1 Advanced Pediatric Critical Care Center, Mehta Multi-Speciality Hospitals, Chennai, Tamil Nadu 600031, India

2 Department of Pediatrics, Mehta Multi-Speciality Hospitals, Chennai, Tamil Nadu, India

3 Institute of Child Health \& Hospital for Children, Madras Medical College, Chennai, Tamil Nadu, India

4 Department of Radiology \& Imaging Services, Mehta Multi-Speciality Hospitals, Chennai, Tamil Nadu, India

5 Department of Pediatric Surgery, Mehta Multi-Speciality Hospitals, Chennai, Tamil Nadu, India
pro-BNP and Troponin T. Due to worsening clinical condition, and negative yield in all other infective (dengue, leptospirosis, typhoid, scrub typhus) workup, we repeated COVID RT-PCR and it turned out to be positive on 10th day of illness. He was treated with $2 \mathrm{~g} / \mathrm{kg}$ of IVIG in view of 'acute inflammation associated with COVID'. Clinical and blood parameters improved and the child recovered over next two days.

While reviewing literature on pediatric cohorts, Dong et al. [2] reported that 'some milder cases had nausea, vomiting and abdominal pain without fever'. In other cohorts, abdominal pain was documented to be $4 \%$ and $5.8 \%$ [3], more as a concomitant symptom like diarrhoea. While reviewing adult data, Lima et al. [4] reported the importance of chest CT evaluation in addition to abdominal $\mathrm{CT}$ in patients presenting as acute abdomen to identify basal pneumonia to ignite a suspicion of COVID-19, not as a primary acute abdomen presentation.

Our index case was a pure abdominal presentation at the onset masquerading as surgical abdomen, persisted through the second week and progressed to shock without any respiratory symptoms. Recent observations all over the world suggest that it can very well be a presentation of 'acute COVID Inflammation' [5]. Our case review supports the plausibility of 'gastrointestinal tract can be the only manifesting organ with varying degrees of severity'.

\section{Compliance with Ethical Standards}

Conflict of Interest None.

\section{References}

1. Mahase E. Covid-19: concerns grow over inflammatory syndrome emerging in children. BMJ. 2020;369:m1710.

2. Dong Y, Mo X, Hu Y, et al. Epidemiology of COVID-19 among children in China. Paediatrics. 2020;145:e20200702. 
3. Parri N, Lenge M, Buonsenso D. Children with Covid-19 in pediatric emergency departments in Italy. N Engl J Med. 2020;383:187-90. https://doi.org/10.1056/NEJMc2007617.

4. Lima DS, Ribeiro MAF Jr, Gallo G. Role of chest CT in patients with acute abdomen during the COVID-19 era. Br J Surg. 2020;107:e196. https://doi.org/10.1002/bjs.11664.
5. Teressa RH, Michello DP, Rabheh AA, et al. COVID-19 associated multisystem inflammatory syndrome in children (MIS-C) guidelines, a Western New York approach. Prog Pediatr Cardiol. 2020;57: 101232. https://doi.org/10.1016/j.ppedcard.2020.101232.

Publisher's Note Springer Nature remains neutral with regard to jurisdictional claims in published maps and institutional affiliations. 